\title{
Akribisch vorbereitete Flexibilität
}

\section{Liebe Leserinnen und Leser,}

ja, es hat sich bei der adhäsion KLEBEN + DICHTEN tatsächlich etwas verändert. Marlene Doobe, die dieses traditionsreiche Fachmagazin mehr als 20 Jahre lang verantwortet, geprägt und ihm ein Gesicht gegeben hat, verabschiedete sich im Sommer dieses Jahres in den wohlverdienten Ruhestand. Als ich ihre Aufgabe vor etwa drei Monaten übernahm, waren mir die damit verbundene Verantwortung und die vielfältigen Herausforderungen durchaus bewusst. Umso erleichterter war ich, als ich feststellte, dass mich nicht nur ein sehr erfolgreiches Magazin, sondern auch eine ausgefeilte medienübergreifende Infrastruktur erwartete. Somit bestehen schon mal die besten Voraussetzungen, um die äußerst erfolgreiche Tätigkeit meiner Vorgängerin fortzuführen und die adhäsion im Sinne der Klebstoff-Community weiterzuentwickeln. Kurz nachdem die Jamaika-Sondierungsgespräche gescheitert waren, ging ein Kommentar von Julia Klöckner (CDU) durch alle Medien. Sie bezeichnete den Ausstieg der FDP als „gut vorbereitete Spontanität“. Aus rhetorischer Sicht ist dies ein schönes und gleichzeitig passendes Oxymoron, um ein nicht ganz überraschendes Ereignis mit einer wohldosierten Prise Sarkasmus zu beschreiben.

Was hat das aber mit der adhäsion zu tun? Nun, ganz ohne Sarkasmus und mit einem ähnlichen, jedoch etwas abgewandelten Ausdruck lässt sich ein wichtiges Merkmal einer Fachzeitschrift definieren: „akribisch vorbereitete Flexibilität“. Dies bedeutet, dass ein Informationsmedium in der Lage sein muss, eingehende aktuelle Meldungen und Beiträge in möglichst kurzer Zeit zu verarbeiten und flexibel - mithilfe etablierter Prozesse - über verschiedene verlagseigene Kanäle bzw. Plattformen zielgerichtet zu verbreiten. Gleichzeitig ist es für ein Magazin von existenzieller Bedeutung, das Themen-Scouting immer weiter zu optimieren, um möglichst frühzeitig neue Trends zu identifizieren und sein Themenspektrum zu ergänzen. Dies ist und bleibt der Anspruch der adhäsion und gelingt selbstverständlich nur durch einen intensiven Austausch mit der entsprechenden Fach-Community. Daher ist es mein primäres Anliegen, die vertrauensvolle Zusammenarbeit mit den Leserinnen und Lesern, Autorinnen und Autoren, den Anzeigenkunden sowie der gesamtem Klebstoff-Szene fortzusetzen.

Ich wünsche Ihnen viel Spaß beim Lesen dieser Jahresendausgabe, eine schöne Adventszeit, ein frohes und besinnliches Weihnachtsfest sowie einen gelungenen Start ins neue Jahr. Bleiben Sie gesund und der adhäsion KLEBEN + DICHTEN auch weiterhin verbunden!

\section{Herzliche Grüße}

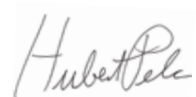

Hubert Pelc hubert.pelc@springernature.com

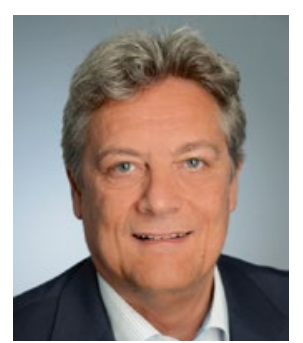

